\title{
Yachting and pleasure crafts in relation to local development and expansion: Marina di Stabia case study
}

\author{
C. Bizzarri ${ }^{1} \&$ D. La Foresta ${ }^{2}$ \\ ${ }^{I}$ Department of Economics and Law, Sapienza University of Rome, Italy \\ ${ }^{2}$ Department of DADAT, Federico II University of Naples, Italy
}

\begin{abstract}
Tourism is increasingly seen as a significant component in the social and economic fabric worldwide. The tourist industry generates important employment opportunities and income within local economies but along with the developments it generates it can also be the cause of decline in the quality of life for residents living in tourist locations.

In the particular case of private yachting and sailing crafts and the harbours built to accommodate them, many social and environmental benefits have been noted. There is for example the increased cash flow that visitors bring and the possibility of using the various terminus points as venues for a series of associated activities and cultural events. However, nautical tourism is not immune from problems caused by increased congestion and pollution as well as damage to places of historic heritage. Moreover, the anticipated economic benefits are uncertain and vulnerable to external factors.

Within this broad range of possible effects, this paper considers the aspect of the relation between private sailing for pleasure and local and regional development, the spin-offs it generates in the territory, its social functions and the additional value it offers the tourist market. The focus is on a manmade harbour in Southern Italy, close to Naples: Marina di Stabia.

Marina di Stabia was born from a cooperation among a group of professional managers from the city of Castellammare di Stabia. The principal aim of their project is the requalification of the disused area to the east of Castellammare, which was once an important metallurgic centre and one of the symbols of the area's industrial supremacy in the past. The harbour was opened in June 2007, and ongoing work continues adding a constant series of improvements.
\end{abstract}


The research is focused on the following points:

- The demand for tourist services in the port

- Marina supply system

- Marina Management models

- Issues of funding for the development of marinas and marine services

- Economic and social impacts caused by nautical tourism.

Keywords: nautical tourism, economics of marinas, environmental impacts of marinas, regional effects of nautical tourism.

\section{Introduction}

Sea-going private crafts spread benefits throughout the various territories wherever they dock. Nautical tourism is not limited to owning a boat and utilizing marine resources and can be listed with all those other forms of tourism which have economic, social and environmental impact on local development.

For this reason the number of berths in harbours or the number of sailing licenses issued cannot be considered an efficient indicator of the value of nautical tourism. The expenditure on land of yachtsmen and owners of private sailing crafts is a much better gauge of evaluation and analysis of economic growth.

Along with a strictly economic analysis that evaluates the possible expenditure of these sea-going tourists it is necessary to show the social and environmental impact of this tourism on the territory. In order to determine these effects, whether local or regional, it is possible to use the concept of physical capacity relative to the number of berths in the harbour and the length of coastline utilized, as well as problems arising from conflicts over resources or rather the loss of resources to other economic sectors which this form of tourism provokes by an exclusive appropriation of marine space. The construction of large ports and their infrastructure pose a limit to the use of marine resources in other sectors such as fishing (through a reduction in biodiversity caused by anchoring that damages the sea floor), bathing and all those seaside activities that require open access to the sea.

As it is not possible to have significant diversification in the use of marine resources it would be preferable to invest in projects that increase territorial and regional development. Nautical tourism produces wealth and expands as far as possible the life cycle of the tourist product

\section{Nautical tourism in Italy}

The study of private sailing for pleasure is quite a recent area of interest in Italy. From an analysis of data which covers only the last four years [1], there has been a notable increase in harbour berths: an increase of 13,000 units from 2007 to 2010. The most dynamic Italian regions in this sector are Liguria and Sicily, even if the Northern Tyrrhenian coast, which takes in Liguria, Tuscany and Sardinia, retain the largest number of berths with respect to other regions. As far as berths in marinas are concerned, apart from the regions already mentioned, 
very significant data for our research comes from Lazio, Campagnia, Basilicata, Emilio Romagna and Puglia: in 2010 an increase was registered of over 100 berths in each of these regions (see table 2.16 page 42 Report On Nautical Tourism 2010). The growth in the sector is also underlined at national level by an increase in the demand for licenses for sea going vessels: from 2003 to 2008 an additional 11,000 licenses were issued [1].

Within Europe Italy is now in third place in the classification for number of private berths coming immediately after France and Spain. In Italy however the proportion of berths to the total number of private vessels is higher than in either France or Spain and while it is true that each boat in theory has the possibility of four berths within national territory it is also true that a large number of these berths are utilised by foreign vessels, the number of which would be very difficult to estimate. Moreover, in recent years the region of Liguria enjoys an extremely high client base: almost $82 \%$ of residents, within the region and on its borders possess their own mooring in local ports.

\section{Economic analysis of yachting and pleasure sailing in Italy}

The phenomenon of pleasure crafts is very interesting from an economic point of view. In comparison to other harbour users most yachtsmen have higher spending power and are mostly educated qualified professionals, often selfemployed (see sampling correlated by Report On Nautical Tourism).

From research sampling carried out by the National Observer On Nautical Tourism and published in the Report On Nautical Tourism it can be seen that expenditure noted by a sample of yachtsmen for port services and refuelling is very high and constitute $80 \%$ of their daily expenditure within the port. The rest of their expenditure (about 20\% of the daily expenses) is very segmented: transport, restaurants, bars and cafés, shopping, entertainment and cultural activities. It is also noteworthy that the cost of transport over land is very low (approximately 10 euro per person) [1]. The spending patterns of yachtsmen is proportionate to a lack of attractions in the outlying territory. If, on the other hand, the principle motive for their journey was to visit the areas beyond the port transport expenditure and in particular private transport such as car rentals or use of taxis would constitute a consistent and very significant expenditure.

However, the average yachtsman directs most of his unessential expenditure on shopping and restaurants and cafés compared to either entertainment or cultural activity. No substantial difference in average expenditure has been noted between yachtsmen whether in transit or local but spending is however much greater than for other forms of nautical tourism. For this reason the yachtsmen are obviously preferable to other sea-going visitors who spend little whether on services strictly attaining to the port or for those of the hinterland. Marina construction is therefore more desirable than multipurpose ports in that the demand is fixed and the private sailor's expenditure is spread around connected business and services and has a higher turnover than for any other type of nautical tourism is maintained. 
From a geographical point of view the Upper Tyrrhenian coast enjoys the highest turnover of all, estimated as being $50 \%$ of the national turnover for all linked business and services.

This advantage however is not of great significance over the gross national or local product because of the high seasonality of the sector. This continues to be a difficult problem for future development.

\section{Analysis of the environmental impact}

From the point of view of the environment the Italian coast line constitutes a very fragile ecosystem and the negative impact of large ports cannot be ignored. If the economic effects of large ports is predictable in the short and medium term, the impact on the environment is gradual and very difficult to demonstrate due to the impossibility of putting an economic evaluation on natural surroundings.

In Italy at the moment multipurpose ports constitute approximately $63 \%$ of all ports. This type of port has a strongly negative environmental impact because of its very large infrastructure and due to the size of the ships and systems of anchoring that cause a significant loss in marine biodiversity. Marinas however being built for smaller vessels put far less pressure on resources and, from an economical point of view, as we have been able to ascertain, enjoy a fixed demand and makes the whole sector more profitable.

The pressure on marine resources and on our coasts moreover is demonstrated by the proportion of the number of berths for every kilometre of cost which is estimated at 20.5 and on the average distance between ports which works out as a port every 14 kilometres. If the spread of ports on one hand represents a possibility of unblocking roads as well as openings for large scale economies, on the other hand there is notably strong pressure on resources and consequent increased loads on capacity [2]. Such a negative impact is amplified by the element of seasonality in nautical tourism and pleasure sailing.

Another problem is born from the conflict between use of resources seeing that the construction of large ports inhibit bathing and fishing for residents along with the practise of some sports such as sub aqua and canoeing. A consequent element of conflict is the protection of natural surroundings. With the formation of ports and marinas these are radically and permanently transformed. It is exactly this characteristic of non-modification which makes the construction of marina or port particularly unsustainable. Should their economic life cycle come to an end due to financial crisis or deficiency in services, the large infrastructure of ports would be very difficult to dismantle and a return the original state of the environment almost impossible.

\section{Nautical tourism in the region of Campania, Italy}

The Campania Region has been characterised for the last ten years by valuable reorganisation in the sector of yachting and pleasure crafts and connected activities. Notwithstanding a deceleration due to the recent financial crisis the 
refurbishing and requalification of present structures has resulted in an increase in the number of vessels along the coast of the region (15,588 units registered in 2009 , representing $15.3 \%$ of total number), and an increase in the number of berths available $(14,405$ berths in 2009 equal to $10.5 \%$ of the national total with an increase from 1997 to 2009 by $58 \%$ ) [3].

However, the positive quantifying data does not adequately describe the actual situation in terms of what this sector can in fact offer nor can the increased registrations of vessels compensate for the highly seasonal peaks in international or national demand, which do not permit high positive economic or occupational returns but only a state of fluctuation

Notwithstanding the efforts of local administration the availability of berths is not adequate to the demand (29 berths per kilometre of coast line as against a national average of 19 kilometres and an average of 101 vessels for every 100 berths compared to a national average of 69.5 for every 100). [4] There is also a widespread lack of organization throughout the region along with a fragmented offer of services in the tourist harbours: a disorderly arrangement of market offers, in terms of services and equipment and the level of the services offered by the infrastructure for yachts and pleasure craft are often unsatisfactory to the needs of the customs. There are an inadequate number of available berths, and many berths designed moreover for coastal vessels of only average dimension. These aspects are indicative of an explicit difficulty in the development of nautical tourism within this region and place the frame of the offer below the national average discouraging any significant flux of foreign tourists who instead crowd into better equipped and decidedly cheaper Turkish, French and Greek marinas. Many world famous locations in this Italian region have a reduced capacity to receive sailing craft and furthermore are almost always characterised by inadequate standards of quality.

To be noted in particular is the casual proliferation of seasonal moorings organised outside the port structures (4600 vessels moored to buoys) or along urban coastlines or along strips of coast intended for bathing, and other methods of inadequate mooring inside ports in terms of security and comfort for users. This phenomenon goes hand in hand with the overcrowding of many organised harbour structures and the minimal use of other port structures, in particular those which were designed for non-tourist uses but are no longer in use having lost their original role and not yet adequately reconverted for private sailing needs.

In some ports a mix of functions can be seen as a resource for private sailing and yachting (for example the cohabitation of dockyards, fishing vessels and pleasure craft) but in other situations is often seen as detrimental and forces decisions on designation (this is especially the case in the presence of both sailing crafts and shellfish farming or in the case of bathing and mooring). Such decisions are further prompted by indicators of overcrowding around closely packed port structures, which cause local disruption and a limit to a stable territorial development.

From these circumstances it is clear to see how in the first place the impossibility of structures to accommodate essential requirements and high 
seasonal peaks has caused a progressive appropriation of parts of the coast by a number of interests incompatible with the private sailing sector and secondly how the spread of market segments often becomes a grey area difficult to control.

However, notwithstanding the scarcity of tourist harbours and low numbers of available berths, strong demand has been registered for moorings, not only by a local customs (permanent moorings) but also by a customs from other Italian regions (transit craft, chartered boats and yachts of large dimension). The private sailing demand is also satisfied by many unauthorised structures, the result of small business improvisation, offering berths or more often moorings attached to buoys in locations of the highest attraction from every point of view.

The number of pleasure craft in transit is however limited by the very high percentage of utilization of infrastructure by permanent customs. This means during the high season regional tourist harbours cannot be relied upon by those private pleasure sailing crafts wishing to organise cruises along the Tyrrhenian coast.

\section{The marina: a useful resource for revitalizing the coastline or a manifestation of environmental impoverishment?}

Without reducing the importance of either the inherent difficulties or consequent criticisms of ports for tourist crafts, it seems evident, however, that there are considerable potential rewards connected with the sector, taking into account both the capacity for expanding the available services and expanding the demand.

In this context, marinas certainly represent a strong opportunity for economic growth for the territory and the local community being able to influence significantly the gross internal product. Possibilities for proliferation of production and employment in this sector are considerable and without doubt higher than in any other sector. In occupational terms it is sufficient to bear in mind that along with the 12,000 working units directly employed in the nautical industry there are linked business concerns with over 80,000 skilled workers [5]. The construction of a sailing vessel represents the first link in a chain which permits the creation of a series of additional activities: commerce, rents, hiring, institutes for professional formation, specialised press, financial services, professional services, conferences and industrial fairs. Port structures themselves require areas for maintenance and repair, security personnel, reception areas and restaurants and bar facilities and represent the most significant factor in this chain of economic growth for the territory. In recent years, in line with the above, tourist harbours have undergone restructuration with the aim of satisfying the increasing demand for new berths while the Italian political authorities have felt the necessity to promote the construction of new shipping ports.

Given the situation an increase in marinas can only be considered as an indispensable condition for consolidating the growth of private pleasure craft enterprise but only in the presence of adequate essential infrastructures to sustain the efforts made by these tourist harbours to attract and welcome yachtsmen and 
their vessels. The integration of tourist harbours with the hinterland and urban areas offering high standard services, including those focusing on environmental control, are fundamental and distinguishing elements for the recognition of the primary role of the "portus", which came into being to do act as exactly that: "the door to the inland territory beyond", offering the opportunity to all the various localities to promote their historic richness, their cultural and gastronomic specialities. In order to succeed in this challenge the coastal territories must be assured of more ports and for existing ports new and improved quays, jetties and berths to be characterised by a management that has an eye for innovation, but also for the requalification of those little utilized or totally unused areas, as well as easy access to all port facilities, the implementation and improvement of services and lastly a guarantee of the defence of the environment and an assurance of the least possible impact on its coastline.

In this sense marinas can represent an important safeguard for the environment in a process of a requalification already in act for some time, along with the continued improvement in services, safety and information.

\section{Marina di Stabia}

The interest shown by various institutions in private pleasure sailing and the linked economic effects is demonstrated in the notable increase in financing for construction or the reconversion of port structures for private sailing. These constructions are often based on overly conventional planning criteria which are in some cases obsolete, but there is however an earnest attempt to find solutions to the growing demand and to take advantage of geographic opportunities and the possibilities the market offers.

To be included in this general trend is the project for the construction of Marina di Castellamare di Stabia. This has been financed by a large public contribution (euro 2,500, 000 from P.O.R budget resources 2000-20006) and also sustained by the participation of a private business consortium. The Marina di Stabia is in the centre of the gulf of Naples and is a unique tourist harbour for both its dimensions and for its technological design which assures a continuous circulation of water and safety for docking. The structure extends over an area of 450,000 square metres, with 1300 berths, of which 161 have protective covering; fuel bunkering for each berth; control towers; Port Authority and docks for repair with ship yard, crane facilities, service slides, reserved parking and land services.

Nine hundred berths are able to receive ships of up to 80 metres in a landscape of incomparable beauty, overlooked by Vesuvius and by Mount Faito, extending from the Sorrento peninsula to Capri and Ischia making this port ideal for those who wish to have a tourist experience with a wide range of choice: diversity in time, in space and substance.

The vicinity to such tourist destinations of excellence as Capri, Amalfi, Positano, Sorrento and to important archaeological sites such as Pompeii, Ercolano and Stabia etc, as well as the possibility to reach easily the Pontine and the Eolie islands make the port a truly rich tourist proposition. Hotels and restaurants, cinemas, commercial centres, sports centres and beauty salons and a 
new railway station to be constructed near to the marina will all contribute to the unique experience.

The sum of all these features make Marina di Stabia the most important tourist port of the new generation in Campania, functioning as a hub for surrounding harbours with inferior moorings and services that exist along the coast but in need of substantial re-equipment.

The superb natural beauty and the high value to the territory of the physical infrastructure of the port are all within the framework of a broad project for recuperation of this length of coast, contributing to the requalification of an area that had an important industrial past, situated where the old Italian metallurgic plants stood on the northern outskirts of Castellammare di Stabia close to the border with Torre Annunziata and near the estuary of the Sarno river. This area characterised in past decades by high density industrial plants underwent a serious crisis during the eighties when many factories were closed and this transformed the zone into a series of crumbling unused buildings and vacant lots. These events, linked to the general impoverishment of the national and regional economic situation, initiated a process of considerable decline for the city, characterised by a high level of unemployment, medium to low levels of education, wide spread petty crime, high urban density, a progressive increase of population and an absence of social services.

Notwithstanding preliminary confidence and expectation the Stabia port, even though a mark of excellence has not yet had the positive bearing on the territory that could be expected from this type of infrastructure.

In the first place the City of Castellammare appears to be totally distanced and physically cut off from the marina. The urban disorder that the construction of the new port imposed on adjacent areas, were not balanced by any immediate attempts to integrate the urban system with that of the port. The zone cushioned between the port and the city is still occupied by industrial plants, some of which are unused, contrasting sharply with the concept of the port. In fact, lines of buildings of considerable length impede access to the sea and this is an obvious obstacle to the aim of re-launching the area with tourism.

There is a concrete risk that this experience is not a portent of economic benefit for both the city and territory but only constitutes an additional aggression in a situation of unstable equilibrium whether for the hydro- geologic organisation of the territory or for the richness if its archaeological sites.

\section{Conclusions}

Notwithstanding the international financial crisis and the numerous difficulties Italy confronts, the Italian marinas continue to grow and represent a potential key factor in processes of revitalising coastal areas. However, while it is now accepted that private sailing for pleasure generates economic benefits equal to $10 \%$ on initial outlay, opinions diverge in the real benefits to the territories involved. In fact, the required complex infrastructure, often too large and designed with the reasoning applied to shopping centres or tourist villages, needs long term heavy investment and often produce constructions that risk rapid 
obsolescence, contributing even more to the degradation of coastal areas without stimulating any favourable development in the neighbouring hinterland. A complete revision of the politics of the sector seems necessary, which should be directed towards a greater flexibility and marinas of smaller dimensions strongly integrated with the entire system of regional transport. The tourist product offered can therefore be further enriched with integrated activities linked to the local identity. These local activities can be centred in those areas of reclaimed coast free of port infrastructure and local communities could be important actors in the process of territorial regeneration. With the right awareness and participation and through the recuperation and maintenance of local uses and activities communities could regain possession of these free zones and contribute to both the control of the environment and the process of revitalisation, requalification and a diversification of territory.

\section{Acknowledgements}

This study is the result of the research of both the authors, but the introduction and the paragraphs 1-2-3-4 are ascribed to C. Bizzarri, while paragraphs 5-6-7 and conclusion are ascribed to D. La Foresta.

\section{References}

[1] Osservatorio Nautico Nazionale, 2010, Rapporto sul turismo nautico, numero 2, Genova

[2] Bennett W., Bristow R. S., 1994, Boating Opportunities a Geographical Analysis of Travel Patterns and Motivations, in: Mahoney E. M., Stynes D. J., 1996 , Recreational Boating Carring Capacity: a Framework for Managing, Inland Lakes, Proceedings of a Workshop, Michingan State University

[3] Osservatorio del turismo della Regione Campania, 2008, I prodotti turistici in Campania: il turismo Nautico, Napoli

[4] Osservatorio del Turismo della Regione Campania, 2008, Il Charter nautico in Campania, Napoli

[5] Ministero delle Infrastrutture e dei Trasporti, 2008, Il diporto nautico in Italia, Roma 